Skin

Appendage

Disorders
Skin Appendage Disord 2015;1:114-116

DOI: $10.1159 / 000439386$
Received: August 7, 2015

Accepted: August 12, 2015

Published online: September 12, 2015

\title{
Subungual Hyperpigmented Nodular Lesion in an Adult's Toe
}

\author{
Leandro Noriega ${ }^{a}$ Nilton Di Chiacchio ${ }^{a}$ Ival Peres Rosa ${ }^{b}$ \\ Alexandre Ozores Michalany ${ }^{a}$ \\ a Dermatology Clinic, Hospital do Servidor Público Municipal de São Paulo, and bepartment of Dermatology, \\ Hospital da Faculdade de Medicina da Universidade Federal de São Paulo, São Paulo, Brazil
}

\section{Question}

A 35-year-old Caucasian male patient, born in São Paulo, was referred to the neoplasm outpatient clinic that is part of the Department of Dermatology, Federal University of São Paulo Hospital, due to a subungual lesion in the fifth right toe. The patient denied symptoms and could not tell when it started; however, he had noticed the lesion 20 days ago. He denied local trauma.

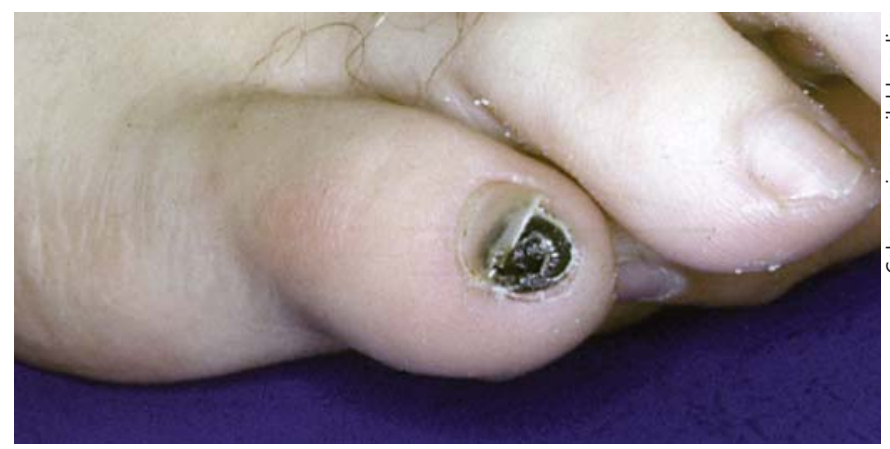

Fig. 1. Subungual hyperpigmented nodular lesion of the fifth right toe.
Upon physical examination, a well-delimited, 10-mm, hyperpigmented (dark brown) nodule, affecting the nail bed and hyponychium of the fifth right toe, was found (fig. 1). Palpation evidenced hardened consistency.

Upon physical examination of the entire body, the patient did not show any other lesions. The X-rays of the affected toe on its anterior-posterior and medium-lateral aspects did not show any bone changes.

We chose to perform a shave biopsy (fig. 2).

What is your diagnosis?

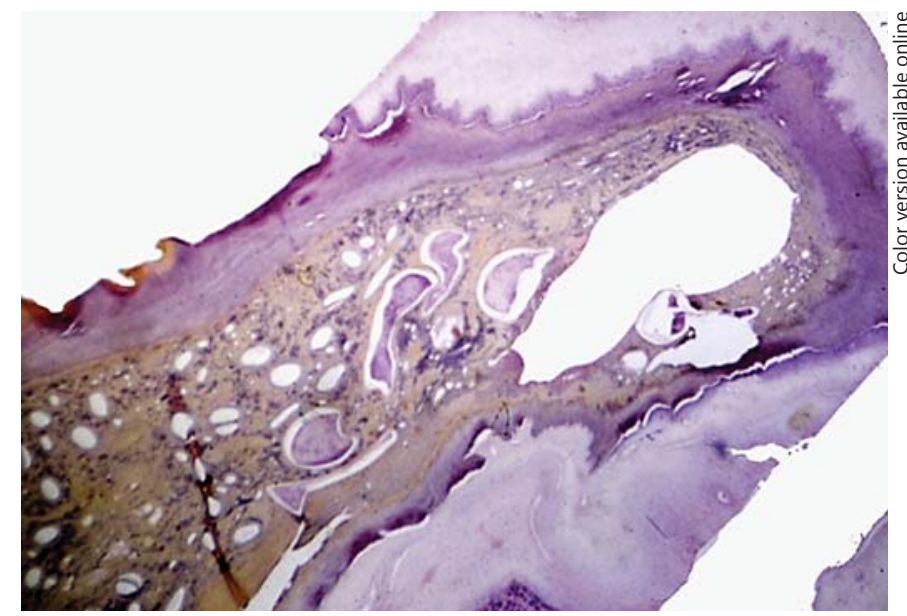

Fig. 2. Histopathology. Hematoxylin and eosin stain. $\times 12.5$. 


\section{Answer}

\section{Subungual tungiasis.}

Tungiasis is a transient ectoparasitic dermatosis, considered as zooanthropophilic, caused by the penetration of Tunga penetrans into the skin $[1,2]$. This ectoparasite is $1 \mathrm{~mm}$ long, hematophagous, lives in the sand, and is more widely disseminated during periods of drought $[2$, $3]$. Its life cycle is approximately 30 days long, going through four biological stages (egg, larva, pupa, and adult) [4].

In Latin American countries, the Caribbean, and SubSaharan Africa, it is considered endemic, constituting a public health problem [5]. In these areas, there is higher prevalence of the disease among 5- to 14-year-old children and a significant association with poor living conditions, low education level, and the presence of animals near the house (dogs, cats, pigs, and rats) $[6,7]$.

Cases diagnosed in North America, Europe, and Australia are usually imported, and they are related to trips to endemic areas $[2,5]$. The increase of trips to tropical regions was associated with the increased incidence of the disease in nonendemic areas, resulting in a diagnostic challenge [8]. The disease is only acquired through epidermal penetration of the fecundated female flea after unprotected contact with contaminated soil [8].

The diagnosis is based on clinical (morphology and topography of the lesions) and epidemiological (living in or traveling to endemic areas) findings $[3,5]$. Typically, it is presented in the form of a whitish papule with adjacent erythema, which shows centrifugal growth. A central, darkened point of up to $6 \mathrm{~mm}$ is observed; between 2 days and 3 weeks from the onset, the parasite's eggs are released. As the lesion grows, the pain, pruritus, and hyperesthesia are intensified. Between 3 and 5 weeks, the flea dies and there is regression of the lesion. This phase is clinically characterized by a blackish crust on the residual lesion $[1,5,9,10]$.

Most of the lesions occur on the feet, with the most commonly affected areas being proximal and lateral nail folds, subungual region, interdigital region, calcaneus, and plantar region [1]. Eventually, the hands, elbows, face, buttocks, and the inguinal or proximal regions of the lower limbs may be affected, mainly in children [2].

According to Heukelbach et al. [11], 23.3-32\% of cases progress with nail deformity and up to $5.5 \%$ with loss of toe nails, especially after severe or repeated occurrences. Other complications include secondary bacterial infection, tetanus, gangrene, and digital deformities $[10$, $11]$.

A Subungual Nodular Lesion of the Toe
In our case, a lesion in a relatively frequent topography of tungiasis was observed; however, the form of presentation of the lesion and the few data on the chronological evolution determined the following as additional diagnostic hypotheses: nodular subungual melanoma, subungual exostosis, hematoma, foreign body, and spinocellular carcinoma. The X-ray analysis ruled out any hypothesis related to bone changes or radiopaque foreign bodies. We chose to conduct a histopathological analysis of the lesion after shave excision, which confirmed the tungiasis diagnosis (in the epidermal region a characteristic exoskeleton of chitin was observed). In this case, it was compatible with the regressive phase of ectoparasitosis.

The surgical extraction is the treatment of choice in situations with few lesions, and subsequently, a topical antibiotic may be applied for 7-10 days, in order to reduce the risk of secondary infections $[1,5,8]$. Our patient progressed without complications. No additional surgical procedure or the use of topical or systemic medications was required.

\section{Statement of Ethics}

The authors have no ethical conflicts to disclose.

\section{Disclosure Statement}

The authors have no conflicts of interest to declare.

\section{Key Words}

Subungual tumor · Tungiasis · Tunga penetrans
1 Veraldi S, Valsecchi M: Imported tungiasis: a report of 19 cases and review of the literature. Int J Dermatol 2007;46:1061-1066.

2 Vallarelli AFA, Souza EM: Disseminated tungiasis. An Bras Dermatol 2011;86:10271028.

3 Criado PR, Landman G, Reis VM, Belda W Jr: Tungiasis under dermoscopy: in vivo and ex vivo examination of the cutaneous infestation due to Tunga penetrans. An Bras Dermatol 2013;88:649-651. 
4 Hoon KS, Fernández MF, Buján MM, Cervini $A B$, Laffargue J, Pierini AM: Tungiasis: a case report. Arch Argent Pediatr 2011;109: 82-84.

5 Sachse MM, Guldbakke KK, Khachemoune A: Tunga penetrans: a stowaway from around the world. J Eur Acad Dermatol Venereol 2007;21:11-16.

6 Verdi M, Benavente D, Gentile J, Omaña S, Zusaeta M: Tungiasis. Rev Argent Dermatol 2008;89:226-233.

7 Muehlen M, Feldmeier H, Wilcke B, Heukelbach J: Identifying risk factors for tungiasis and heavy infestation in a resource-poor community in northeast Brazil. Trans R Soc Trop Med Hyg 2006; 100:371-380.

8 Fich F, Del Barrio-Díaz P, Kam S, Celle V, Concha M, Kolbach M, et al: Tungiasis, an emerging tropical disease in Chile. Three imported cases reports. Rev Chil Infectol 2013; 30:676-679.

9 Eisele M, Heukelbach J, Van Marck E, Mehlhorn H, Meckes O, Franck S, Feldmeier $\mathrm{H}$ : Investigations on the biology, epidemiology, pathology and control of Tunga penetrans in Brazil. I. Natural history of tungiasis in man. Parasitol Res 2003;90:8799.

10 Feldmeier H, Eisele M, Van Marck E, Mehlhorn H, Ribeiro R, Heukelbach J: Investigations on the biology, epidemiology, pathology and control of Tunga penetrans in Brazil. IV. Clinical and histopathology. Parasitol Res 2004;94:275-282.

11 Heukelbach J, Jackson A, Ariza L, Calheiros CML, Soares VL, Feldmeier H: Epidemiology and clinical aspects of tungiasis (sand flea infestation) in Alagoas State, Brazil. J Infect Dev Ctries 2007;1:202-209. 